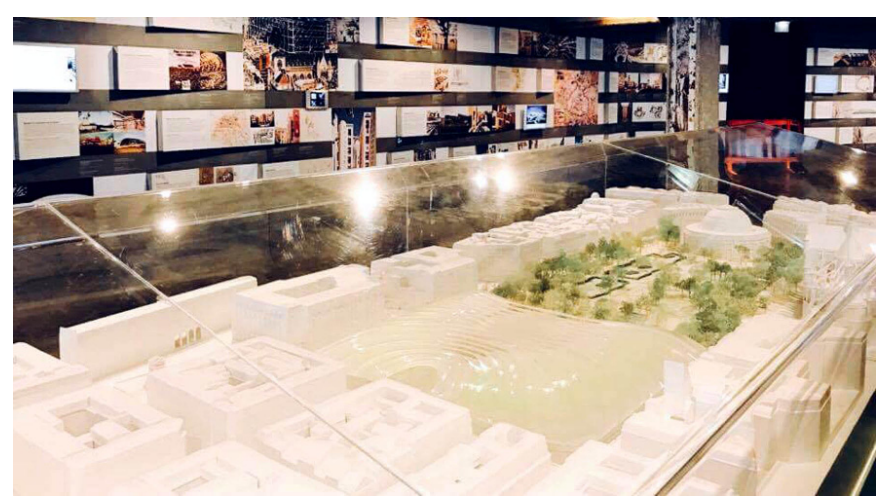

\title{
RÉINVENTER PARIS:
}

EXPOSITION DES RESULTAS

DE L'APPEL À PROJETS

URBAINS INNOVANTS.

Pavillion de L'arsenal. Paris, FRANÇA. 4 DE FEVEREIRO DE $20 I 6$ 8 DE MAIO DE $20 I 6$

Adalberto da Silva Retto Júnior

I66

\section{Reinventar Paris}

Era de se esperar que após os ataques terroristas, Paris estaria fechada em si mesma, como capital de um país em crise, sem nenhuma capacidade de pensar o próprio futuro. Ledo engano. A mostra Réinventer Paris, com os 23 dos 815 projetos que participaram da competição internacional lançada pela prefeita socialista Anne Hidalgo, demonstra algo diametralmente oposto que, para alguns críticos, significa uma nova forma de abordar o desenvolvimento urbano.

Como enfatiza seu braço direito, Jean-Louis Missika, Coordenador da Comissão de Urbanismo, Arquitetura, Projetos e Desenvolvimento Econômico da Prefeitura de Paris:

Uma cidade como Paris deve ser capaz de se reinventar a qualquer momento, a fim de enfrentar cada desafio possível. Por exemplo, em termos de habitação, e em todos os assuntos que afetam a densidade populacional, a diversidade, a energia ou capacidade de adaptação, devese encontrar novos modos coletivos, que irão moldar o futuro da metrópole. (MISSIKA, 2017)

A mostra localizada no saguão principal do Pavillon de l'Arsenale, coração do tradicional bairro do Marais (4o. Arrodissement), além das grandes projeções sobre o território da intervenção, possui parede interativa que permite aos vários usuários a exploração simultanêa de diferentes projetos. Em paralelo, como comumente ocorre em concursos desse porte, durante três meses organizou-se um programa de conferências e encontros com as equipes vencedoras, proporcionando a todos maior compreensão dos projetos e da forma de viabilização a partir dos denominados "atores da inovação".

As rápidas mudanças dos estilos de vida na cidade requerem uma inovação nos modos de viver, com a criação de espaços de convialidade compartilhada, e nos modos de trabalhar, através coworking (o compartilhamento do ambiente de trabalho para diversas atividades independentes), o teletrabalho, compartilhamento de showroom, dos fab lab (pequenas oficinas que oferecem serviços personalizados de fabricação digital) e os temporary shops. (MISSIKA, 2017).

DOI: HTTP://DX.DOI.ORG/IO. I I606/ISSN.23I 7-2762.v24i43p I66-I68 
O resultado do concurso demonstra a grandiosidade da proposta, inclusive no que há em matéria de regeneração urbana: os vinte e três sítios - "vazios urbanos" e edifícios em desuso - de propriedade da prefeitura são oferecidos como oportunidade para repensar as funções do território, desenvolvendo novas sinergias entre o público, privado e social. Assim, frente às mudanças sociais, econômicas e culturais em curso, os projetos assumem o objetivo de reorganizar o espaço habitado com base em novos princípios e em hodiernas lógicas de desenvolvimento. A filosofia do maxiprojeto, como está sendo denominado, é a de não mais dar a cessão de uso ao construtor, para que ele realize somente aquilo que achar interessante ou de forma compatível apenas com as normativas locais e interesses individuais; e sim, a realização de obras destinadas ao interesse público, projetadas não por arqstars, mas a partir de concurso aberto para diversos profissionais.

A selecionada série de projetos reitera três premissas, consolidadas a partir de concursos internacionais entre os anos de 1980 e de 1990, como o paradigmático resultado do concurso para o Parc de la Villette, cujo confronto final entre as propostas dos arquitetos Rem Koolhaas e Bernard Tschumi, trouxe à luz uma refinada reflexão - não só sobre o debate do parque do Século XXI, mas a respeito da nova concepção de espaço a ser reabilitado na Cidade Contemporânea.

I - Que a "cidade contemporânea" é aquela apta a ser reescrita em virtude dos sinais progressivamente inscritos, lidos e reinterpretados. E tal como um lugar revestido de sentido, de valor simbólico, político, social e econômico; nessa cidade cada tentativa de projeto internalizado na paisagem estabelece um diálogo com as camadas de tempos, em grau de viver, de regenerar-se e de absorver "novos significados", em contante operação de jogo de escalas;

II - O território afirma-se como laboratório e imediatamente consolida nova dimensão estrutural ao pensamento projetual do urbanismo: marca a natureza do bem comum, entendido como extraordinário patrimônio de recursos que envolvem componentes ecológicos, naturais, econômicos e culturais. Inclusive, além de colocar-se como forma interpretativa para compreender a mutação contemporânea, ele permite ler a constante interação entre sedimentação histórica e práticas tradicionais e entre natureza e construído.

Temos uma verdadeira hibridação de saberes para o projeto, partindo não somente do uso da História, da Geografia - a serviço da concepção de paisagem com infraestruturas verdes, como também, das ciências participativas como a Pedagogia, essa muito útil para sedimentação e discussão da ecologia urbana;

III - Que para planejar a Cidade Contemporânea é necessário operar prefiguração, na qual a leitura do fragmento possa efetivamente delinear hipóteses futuras de transformação, não exclusivamente do ponto de vista técnico, mas social e político.

A noção de devir, que aparecerá na palavra "cenário", explicitará que entre as diversas formas de conhecimento, o projeto revela-se com aspectos específicos: como instrumento de leitura e de inovação conceitual, portanto, como produtor de conhecimento rediscutindo a imbricação entre análise e projeto.

Entre os diversos dispositivos e operações projetuais, talvez a construção de cenários provoque momentos no quais o projeto possa apresentar-se com maior clareza, com sequência coerente e com explícitas hipóteses futuras. Projetar, assim como, reconhecer e descrever uma situação ou mesmo formular uma 
interpretação de um fenômeno, implica na utilização e escolha de diversas possibilidades de construção do raciocínio.

Nesse sentido, dois novos aspectos com relação às questões urbanas emergem como balizadores da proposta: a inovação no centro dos projetos, não somente do ponto de vista construtivo, tecnológico, mas principalmente social e juridicial-financeiro; e a amplitude geográfica do empreendimento, que em números remontam às grandes reformas por quais passaram a Ville Lumière nos Grand Travaux do Barão Haussmann e Napoleão III, que alteraram profundamente a fisicalidade da cidade.

Da perspectiva urbanística, o objetivo não é somente a requalificação, mas a criação de grandes infraestruturas verdes no tecido da capital, com a formação de corredores com Green Building: paredes de plantas, telhados verdes (para uma área de mais de 26.000 metros quadrados), jardins urbanos, uso extensivo de madeira, acquaponiche culturas e muitíssima atenção para eficiência energética; aliás, um total de 1341 novas unidades habitacionais, pelo menos metade construída a baixo custo, foram projetadas tanto no centro, como na zona periférica. Um "nicho de biodiversidade" que vinculará Paris ao seu entorno, a partir da união inédita e simbólica entre a prefeitura de Paris e a de Neuilly-sur-Seine, delineando a fronteira verde do interior dos antigos muros à parte externa, dando uma atmosfera urbana.

Nessa mesma linha, concebido pelo arquiteto japonês Sou Fujimoto, "mil árvores" é um dos projetos mais emblemáticos, pois propõe a construção de um mega edifício, onde em seu terraço terá um parque composto de aproximadamente 30 chalés individuais. Em uma operação gigantesca de financiamento de projetos, de acordo com os cálculos do Diretor de Finanças, Julien Bargeton, esses devem trazer para os cofres da prefeitura cerca de 565 milhões de euros sob a forma de custos em infraestrutura.

As intervenções ambiciosas escolhidas para reinventar a Paris do futuro são a prova clara do que realmente pode ocasionar mudança de ritmo, alteração nos caminhos para o desenvolvimento de uma cidade, tomando por base a capacidade de instalar um verdadeiro laboratório. Por trás dos projetos selecionados encontra-se uma escolha política bem clara, que parte de uma administração que é capaz de planejar o futuro (tanto em médio e longo prazo) e acima de tudo, sabe colocá-la no centro do debate entre o público de especialista e outros tipos de atores locais.

\section{Referências}

MISSIKA, Jean-Louis. La profondeur, nouvelle dimension de l'urbanisme parisien. In: Mairie Paris, reinventer.paris: Les dessous de Paris. Disponível em: <http://www.reinventer.paris>. Acesso em: 4 nov. 2017.

Adalberto da Silva Retto Júnior

Faculdade de Arquitetura, Artes e Comunicação. Universidade Estadual Paulista. Bauru, SP.

rettojr@faac.unesp.br 